\title{
Peran Musyawarah Guru Mata Pelajaran dalam Meningkatkan Profesionalisme Guru Sosiologi di Kota Kupang
}

\author{
Fransisca Susanti Maure, Arifin*, Amirullah Datuk \\ Pendidikan Sosiologi, Universitas Muhammadiyah Kupang \\ *rifilatihan@yahoo.com
}

\begin{abstract}
Abstrak
Kiprah Musyawarah Guru Mata Pelajaran (MGMP) Sosiologi di Kota Kupang belum dirasakan optimal oleh anggota MGMP. Perannya adalah meningkatan kompetensi Profesional guru sosiologi. Penelitian ini dilaksanakan untuk memperoleh gambaran tentang peran MGMP sosiologi dan kendala-kendala yang dihadapinya dalam meningkatkan kompetensi profesionalisme guru sosiologi. Hasil penelitian menunjukkan bahwa MGMP sosiologi Kota Kupang berperan aktif dalam meningkatkan kinerja guru sosiologi, hal ini ditunjukkan dengan peran yang dilakukan oleh MGMP sosiologi diantaranya: melakukan pengkajian terhadap inovasi model dan media pembelajaran, pelatihan dalam pembuatan perangkat pembelajaran, diklat, workshop, pembuatan soal-soal ujian, pelatihan dan pendalaman kurikulum 2013 beserta model dan evaluasinya, dan melakukan bimbingan terbatas/latihan mengajar secara bergantian yang dibimbing oleh guru senior. Dengan demikian MGMP sosiologi berperan serta dalam meningkatkan kompetensi profesionalisme guru sosiologi. Beberapa kendala yang dihadapi dalam melaksanakan perannya diantaranya: (a) kurangnya motivasi guru sosiologi dalam meningkatkan profesionalisme melalui MGMP, (b) kurangnya kerja sama antara anggota dan badan pengurus MGMP, (c) jadwal pertemuan MGMP yang bertepatan dengan jam mengajar guru sosiologi di sekolah, (d) kurangnya dana operasional dalam menunjang kegiatan yang diadakan oleh MGMP sosiologi di Kota Kupang.
\end{abstract}

Kata kunci: guru sosiologi, MGMP, peran, profesionalisme.

Dikirim: 17 Oktober 2020

Direvisi: 10 Desember 2020

Diterima: 18 Desember 2020

Identitas Artikel:

Maure, F. S., Arifin, A., \& Datuk, A. (2021). Peran Musyawarah Guru Mata Pelajaran dalam Meningkatkan Profesionalisme Guru Sosiologi di Kota Kupang. Jurnal Ilmu Pendidikan (JIP) STKIP Kusuma Negara, 12(2), 111-118.

\section{PENDAHULUAN}

Pendidikan menjadi unsur pokok dalam suatu negara karena maju tidaknya suatu negara dapat dilihat dari kualitas pendidikannya. Pendidikan juga diharapkan mampu mewujudkan beragamnya masyarakat digital saat ini, tidak hanya aspek kognitif peserta didik semata, melainkan juga pada aspek afektif maupun psikomotorik. Dalam Undang-Undang RI No 20 tahun 2003 tentang Sistem Pendidikan Nasional Pasal 1 ayat 1, menyatakan bahwa pendidikan adalah usaha sadar dan terencana untuk mewujudkan suasana belajar dan proses pembelajaran agar peserta didik secara aktif mengembangkan potensi dirinya untuk memiliki kekuatan spiritual keagamaan, pengendalian diri, kepribadian, kecerdasan, akhlak mulia serta keterampilan yang diperlukan dirinya, masyarakat, bangsa dan negara.

Guru menjadi kunci utama dalam mencerdaskan generasi bangsa di Indonesia karena dengan guru yang berkualitas akan mewujudkan generasi yang bertakwa 
kepada Tuhan dan siap menghadapi setiap perubahan zaman yang terus menerus berkembang. Oleh karena itu, di dunia pendidikan diperlukan sosok guru yang profesional dalam bidangnya. Hal yang sama juga dirumuskan dalam UU RI No. 14 Tahun 2005 tentang Guru dan Dosen pada Pasal 8, bahwa guru wajib memiliki kualifikasi akademik, kompetensi, sertifikasi pendidik, sehat jasmani dan rohani serta memiliki kemampuan untuk mewujudkan tujuan pendidikan Nasional.

Sanjaya (dalam Apriyani, 2016) mengungkapkan bahwa proses belajar mengajar yang efektif terutama untuk mencapai tujuan pendidikan adalah diperlukan seorang guru yang berkompeten di bidangnya. Seorang guru yang profesional harus memiliki kemampuan dalam mengelola kelas dengan baik. Guru tidak hanya berperan sebagai model atau teladan bagi para peserta didik, tetapi juga sebagai pengelola pembelajaran (manager of learning). Dalam hal ini, guru menjadi unsur pokok dalam proses pendidikan, karena guru merupakan faktor penentu dan utama dalam mencapai mutu pendidikan.

Ambarjaya (dalam Israwati, 2014) mengungkapkan bahwa di dalam dunia pendidikan diperlukan seorang guru sebagai perantara untuk memberi pengetahuan kepada peserta didik. Dari pendapat di atas, secara tidak langsung mengharuskan para guru dan pemerintahan untuk terus meningkatkan profesionalisme melalui berbagai organisasi-organisasi. Peningkatan mutu pendidikan tidak cukup hanya dilakukan oleh pemerintah dengan memberikan dana untuk meningkatkan mutu pendidikan Indonesia, namun perencanaan, pelaksanaan hingga evaluasi harus terus diupayakan dengan seoptimal mungkin.

Organisasi profesi guru juga diatur dalam UU Nomor 14 Tahun 2005 Tentang Guru dan Dosen pada pasal 1 ayat 13 yang menyatakan bahwa organisasi profesi guru adalah perkumpulan yang berbadan hukum yang didirikan dan diurus oleh guru untuk mengembangkan profesionalitas guru. Saondi (dalam Wulandari, 2017) mengungkapkan bahwa organisasi atau wadah komunikasi profesi ini sangat diperlukan dalam memberikan kontribusi guna meningkatan kemampuan, wawasan pengetahuan serta pemahaman guru terhadap materi yang diajarkan dan pengembangannya. Hal yang sama juga dijelaskan oleh Basuni (dalam Muktar, 2019) bahwa organisasi profesi guru menjadi salah satu wadah yang tepat dalam melakukan misi peningkatan mutu pendidikan di Indonesia, karena keberadaannya memiliki sebuah tujuan utama meningkatkan mutu profesi guru dalam melaksanakan tugas pencapaian tujuan pendidikan nasional serta mempertinggi kesadaran, sikap, dan kesejahteraan guru sebagaimana dikatakan. Supriadi (dalam Mutmainah, 2011) juga mengunggkapkan bahwa, dalam meningkatkan profesionalisme guru dan mutu pendidikan, dapat dilakukan dengan mengoptimalkan fungsi dan peran kegiatan dalam bentuk Kelompok Kerja Guru (KKG) dan MGMP, yang memungkinkan bagi para guru dalam memecahkan setiap masalah-masalah yang dihadapi dalam proses belajar mengajar. Kualitas para guru dapat meningkat jika forum guru seperti MGMP dan forum lainnya dilakukan secara intensif. Dengan merevitalisasi forum musyawarah guru diharapkan semua persoalan yang dialami oleh para guru dan peserta didik dalam proses pembelajaran di sekolah maupun di lingkungan masyarakat dapat diselesaikan agar dapat meningkatkan kualitas mutu pendidikan.

Hal ini dapat dipahami bahwa MGMP dalam setiap Kabupaten atau Kota diharapkan mampu membentuk karakter para guru agar lebih profesional, serta mampu meningkatkan profesionalisme para guru terutama dalam pengembangan 
kurikulum yang terus berganti sesuai dengan perubahan zaman. Dengan adanya wadah MGMP Sosiologi di Kota Kupang seharusnya dapat dimanfaatkan secara baik oleh para guru sosiologi di Kota Kupang untuk berperan aktif dalam setiap kegiatan yang diadakan oleh wadah MGMP.

Merujuk pada penelitian terdahulu, hal yang meyakinkan bahwa MGMP dapat menjadi wadah yang dapat meningkatkan profesionalisme guru. Penelitian Husna (2016) menyimpulkan bahwa MGMP Pendidikan Agama Islam (PAI) berperan aktif dalam meningkatkan kemampuan pengembangan materi pembelajaran bagi Guru PAI melalui kegiatan MGMP yakni: (1) mengadakan pelatihan pembuatan Karya Tulis Ilmiah (KTI); (2) MGMP sebagai forum supervisi kolegial guru PAI; (3) MGMP berperan dalam pelatihan pembuatan perangkat pembelajaran. Penelitian Anwar (2011) menyimpulkan bahwa MGMP berpengaruh signifikan terhadap profesionalisme guru sebesar $27,7 \%$, dan sisanya sebesar $73,3,00 \%$ dipengaruhi oleh faktor lain yang tidak diteliti dalam penelitian ini, misalnya sarana dan prasarana sekolah. MGMP mempengaruhi kinerja mengajar guru sebesar $10,9 \%$, dan sisanya sebesar $89,1 \%$ dipengaruhi oleh faktor lain yang tidak diteliti dalam penelitian ini, misalnya media dan alat pembelajaran. Selanjutnya studi Mutmainah (2011) menyimpulkan bahwa upaya-upaya MGMP Sejarah dalam pengembangan kompetensi profesional guru sejarah di Kabupaten Rembang adalah melalui kegiatan program kerja yang sudah signifikan dan sesuai dengan kubutuhan guru. Program tersebut yaitu pembahasan silabus, pembuatan perangkat KBM, pembuatan Modul, pembuatan soal semester, studi lapangan situs sejarah, pembuatan VCD pembelajaran. Lebih lanjut, kerja sama yang dilakukan oleh MGMP dengan Masyarakat Sejarawan Indonesia (MSI) Komisariat Rembang menambah wawasan dan manfaat yang sangat baik bagi anggota MGMP, serta MGMP mempunyai peranan dalam proses sertifikasi guru yaitu dapat memberikan surat keterangan bagi anggota untuk Penetapan Angka Kredit (PAK).

Berdasarkan hasil observasi awal yang dilakukan di SMA Negeri 5 Kupang dan SMA Negeri 3 Kupang bahwa, forum MGMP sosiologi Kota Kupang belum memberi kontribusi terhadap peningkatan kemampuan atau kompetensi guru sosiologi. Masih ada guru sosiologi yang menggunakan metode mengajar ceramah, serta tidak berlatar belakang dari pendidikan sosiologi atau nonpendidikan. Perbedaan dari setiap latar belakang pendidikan yang dimiliki oleh para guru sosiologi di Kota Kupang dengan mata pelajaran yang diampunya, tentu akan menimbulkan berbagai masalah dalam proses pembelajaran, karena minimnya kompetensi mengajar yang dimiliki oleh guru sosiologi. Oleh karena itu, MGMP sosiologi berperan penting sebagai wadah dalam meningkatkan kompetensi guru. Namun, MGMP sosiologi Kota Kupang kurang berjalan dengan baik karena berbagai kendala yang dihadapi sehingga menyebabkan MGMP kurang berjalan dengan efektif.

\section{METODE PENELITIAN}

Jenis penelitian ini adalah penelitian kualitatif dengan pendekatan deskriptif, yaitu penelitian yang bersifat menggambarkan sebuah fenomena pada suatu peristiwa atau sebuah kalimat, yang disusun secara cermat dan sistematis mulai dari menghimpun data hingga menafsirkan dan melaporkan hasil penelitian untuk 
memperoleh data yang akurat. Menurut Bog \& Taylor (dalam Mahmud, 2013) mengungkapkan bahwa, metodologi kualitatif sebagai jenis penelitian yang menghasilkan data-data deskriptif yang terdiri dari kata-kata tertulis atau lisan dari seseorang dan perilaku yang dapat diamati.

Teknik pengumpulan data adalah dengan wawancara, observasi, dan dokumentasi. Wawancara digunakan untuk memperoleh data tentang peran MGMP dalam meningkatkan profesionalisme guru sosiologi di Kota Kupang. Jenis wawancara adalah in-depth interview atau wawancara mendalam. Patton (dalam Mutmainah, 2011), menjelaskan bahwa wawancara mendalam lebih bersifat terbuka dan lentur, tidak berada pada suasana yang formal, dan bisa dilakukan berulang pada informan yang sama. Adapun yang menjadi narasumber dalam penelitian ini adalah Wakil MGMP sosiologi, Sekretaris MGMP sosiologi, dan 4 (empat) guru sosiologi yang merupakan anggota MGMP sosiologi di Kota Kupang. Observasi yang dilakukan dalam penelitian ini adalah aktivitas apa saja yang terjadi dalam wadah MGMP sosiologi tentang perannya dalam meningkatkan profesionalisme guru. Adapun dokumentasi yang dimaksud dalam penelitian ini adalah struktur organisasi MGMP, Program Kerja, daftar hadir kegiatan, dan dokumen lain yang relevan dengan penelitian ini baik yang bersumber pada buku maupun internet. Sedangkan teknik analisis data menggunakan analisis interaktif model Miles \& Huberman dengan tahapan reduksi data, penyajian data, dan penarikan kesimpulan atau verifikasi. Untuk memastikan keabsahan data penelitian, peneliti menggunakan teknik triangulasi sumber.

\section{HASIL DAN PEMBAHASAN}

\section{MGMP Sosiologi dalam Meningkatkan Profesionalisme Guru Sosiologi}

Berdasarkan keadaan yang ditemukan di lapangan, MGMP sosiologi Kota Kupang memiliki 6 (enam) peran penting dalam meningkatkan profesionalisme guru sosiologi, keenam peran tersebut adalah: (a) Peran MGMP sebagai reformator; (b) Peran MGMP sebagai mediator; (3) Peran MGMP sebagai supporting agency; (4) Peran MGMP sebagai kolaborator; (5) Peran MGMP sebagai evaluator dan developer school reform; (5) Peran MGMP sebagai clinical dan academic supervisor.

Dari keenam peran MGMP di atas sangat berperan penting dalam meningkatkan profesionalisme guru sosiologi di Kota Kupang. Namun dari hasil penelitian yang ditemukan di lapangan, baru terdapat lima peran yang sudah terealisasikan dalam pelaksanaan MGMP. Sedangkan kolaborator belum dilaksanakan oleh MGMP sosiologi, karena berdirinya MGMP sosiologi masih terbilang sangat baru dibentuk, ketimbang wadah MGMP lainnya yang sudah terlebih dahulu dibentuk, sehingga wadah MGMP belum memiliki dana penunjang kegiatan yang cukup.

\section{Peran MGMP Sosiologi sebagai Reformator}

MGMP sebagai reformator berperan dalam melakukan perubahan sebagai upaya menciptakan pembelajaran yang efektif dan menyenangkan. Adapun peran MGMP sosiologi Kota Kupang sebagai reformator sebagaimana yang disampaikan oleh informan AHH: "MGMP sosiologi memberi perubahan dan 
pengembangan diri kepada guru-guru sosiologi melalui beberapa program yang dilaksanakan oleh MGMP, dengan tujuan agar MGMP sosiologi ini mampu meningkatkan kompetensi guru sosiologi dalam menciptakan pembelajaran yang efektif dan menyenangkan dengan pengenalan metode-metode pembelajaran, yang sesuai dengan kurikulum yang berlaku saat ini".

Berdasarkan uraian data di atas, MGMP sosiologi Kota Kupang sebagai reformator, yang berperan untuk memberikan dukungan kepada guru sosiologi dengan kegiatan-kegiatan yang diadakan dalam setiap kegiatan seperti diklat, workhop, penyusunan perangkat pembelajaran dan kegiatan lainnya sehingga guru dapat menciptakan pembelajaran yang efektif dan menyenangkan bagi peserta didik.

Penjelasan di atas relevan dengan hasil penelitian Wardani (2019) yang mengatakan bahwa, peran MGMP sebagai reformator dengan pembinaan dan pengarahan mengenai kurikulum 2013, penyusunan perangkat pembelajaran dengan metode-metode pembelajaran yang bervariatif, diskusi teman sejawat mengenai persoalan yang dihadapi oleh guru sosiologi, workhop, diklat dan kegiatan-kegiatan lainnya.

\section{Peran MGMP Sosiologi sebagai Mediator}

MGMP sosiologi juga berperan sebagai media dalam meningkatkan kompetensi guru sosiologi dalam berbagi informasi dan pengalaman, mengenai perangkat pembelajaran, terutama dalam pegembangan kurikulum 2013. Sebagaimana yang disampaikan oleh $\mathrm{HH}$, mengenai peran MGMP sebagai mediator: "MGMP sosiologi sebagai mediator atau penghubung bagi guru-guru sosiologi dalam meningkatkan kompetensi guru melalui program-program yang diadakan oleh MGMP sosiologi seperti pelatihan dalam pembuatan perangkat pembelajaran, diklat,workshop, pembuatan soal-soal ujian, diskusi mengenai materi sosiologi serta penerapan pengembangan kurikulum 2013 dalam metode pembelajaran, yang seiring berubah sesuai dengan perkembangan jaman, sehingga para guru dituntut untuk terus mengembangkan kemampuannya melalui wadah profesi guru seperti MGMP". Berdasarkan uraian di atas, MGMP sosiologi Kota Kupang sebagai mediator, yang mewadahi para guru sosiologi dengan kegiatan-kegiatan yang dapat meningkatkan profesionalisme guru sosilogi. Penjelasan di atas relevan dengan penelitian Arba (2018) yang menjelaskan bahwa MGMP sebagai media untuk menghasilkan guru-guru yang profesional dengan mengadakan beberapa kegiatan seperti diklat dan pelatihan, agar dapat menambah kreatifitas guru dalam proses pembelajaran.

\section{Peran MGMP Sosiologi sebagai Supporting Agency}

MGMP sosiologi sebagai supporting agency yang mendukung para guru untuk berinovasi dengan meningkatkan kemampuan mengajar, baik itu secara tenaga maupun secara pemikiran. Adapun peran MGMP sosiologi Kota Kupang sebagai supporting agency sebagaimana yang diunggkapkan oleh Informan AHH bahwa: Dukungan yang diberikan MGMP sosiologi Kota Kupang yaitu dengan cara mengadakan kegiatan seperti diklat, workshop, penyusunan perangkat pembelajaran dan penyusunan soal-soal ujian, serta diskusi mengenai metodemetode pembelajaran yang efektif dengan kurikulum 2013, sehingga guru dapat lebih berinovasi baik dalam manejemen kelas maupun manejemen sekolah. Hal 
yang menarik juga dilakukan adalah latihan mengajar terbatas bagi guru sosiologi yang dibimbing langsung oleh guru-guru senior.

Berdasarkan uraian di atas, MGMP sosiologi sebagai Supporting agency, yang menjadi perantara dalam mendukung perkembangan profesionalisme guru dengan kegiatan-kegiatan yang diadakan agar guru mampu berinovasi, baik itu dalam lingkungan sekolah maupun dalam proses pembelajaran di kelas. Penjelasan ini sesuai dengan penelitian Djulaiqha (2016), yang mengatakan bahwa MGMP membantu para guru dalam melakukan berbagai inovasi dalam manajemen kelas maupun manajemen sekolah dengan mengadakan kegiatan mengembangkan metode pembelajaran yang efektif dan menyenangkan baik bagi guru maupun bagi peserta didik.

\section{Peran MGMP Sosiologi sebagai Evaluator dan Developer School Reform}

MGMP sebagai evaluator dan developer reform dalam melakukan kegiatan evaluasi dan mengembangkan reformasi sekolah (MBS) serta implementasi kurikulum 2013. Adapun peran MGMP sebagai evaluator dan developer school reform sebagaimana yang diungkapkan oleh Informan $\mathrm{AHH}$ bahwa: Kegiatan evaluasi diawali dengan mengukur sejauh mana efektifitas penggunaan alat penilaian yang digunakan oleh masing-masing guru sosiologi di sekolah dalam proses pembelajaran, sehingga ketika ada kekeliruan atau kesulitan dalam mengukur hasil belajar peserta didik maka kami para guru sosiologi saling berdiskusi dalam mencari alternatif yang tepat dalam melakukan evaluasi terhadap hasil belajar peserta didik dalam pembelajaran sosiologi. Selain evaluasi MGMP juga sebagai pengembangan reformasi sekolah melalui kegiatan-kegiatan yang diadakan oleh MGMP sosiologi, serta membantu para guru dalam mengimplementasi kurikulum 2013 dalam proses pembelajaran.

Dalam meningkatkan profesionalisme guru sosiologi di Kota Kupang, MGMP sosiologi Kota Kupang juga melakukan kegiatan evaluasi, mengembangkan reformasi sekolah dalam manajemen berbasis sekolah (MBS) serta dalam mengimplementasi kurikulum 2013 kepada guru sosiologi. Penjelasan di atas sesuai dengan penelitian Arba (2018), yang menjelaskan bahwa MGMP sebagai evaluator dan developer school reform bagi guru dan sekolah, yaitu dengan kegiatan penilaian hasil belajar peserta didik pada masing-masing sekolah, serta melakukan pengembangan reformasi sekolah dengan pelatihan-pelatihan khusus seperti diklat, workshop dan kegiatan lainnya, agar dapat berdampak besar bagi peserta didik dan juga sekolah yang diajarnya.

\section{Peran MGMP Sosiologi sebagai Clinical dan Academic supervisor}

MGMP sosiologi sebagai clinical dan academic supervisor, dimana MGMP memberikan supervisi atau pengawasan serta pengarahan dengan pendekatan penilaian yang diperlukan dan sesuai dengan situasi dan kondisi guru sosiologi.Adapun peran MGMP sosiologi Kota Kupang sebagai clinical dan academic supervisor, sebagaimana yang diunggkapkan oleh salah satu informan bahwa: Pengawasan yang dilakukan MGMP sosiologi dalam meningkatkan profesionalisme guru yaitu dengan memberi pengarahan pada penyusunan perangkat pembelajaran, pembinaan mengenai penggunaan metode-metode pembelajaran yang sesuai dengan kurikulum 2013, diklat, dan workshop 
mengenai kurikulum 2013, yang sesuai dengan kebutuhan guru sehingga dapat bermanfaat bagi para guru sosiologi di Kota Kupang.

Berdasarkan pendapat diatas, MGMP sosiologi Kota Kupang memberikan pengarahan dan pembinaan yang sesuai dengan kondisi dan situasi yang dihadapi oleh guru-guru sosiologi Kota Kupang,sehingga mampu meningkatkan kemampuan mengajar guru. Uraian di atas relevan dengan penelitian Okyulianti (2017), yang menjelaskan bahwa MGMP memberi pengarahan dan pembinaan yang dilakukan harus sesuai dengan kondisi di lapangan, agar dapat bermanfaat bagi guru sosiologi karena MGMP bukan sekedar organisasi yang mewadahi para guru tetapi juga memberi kontribusi yang positif bagi guru dalam meningkatkan kompetensi.

\section{Kendala MGMP Sosiologi dalam Meningkatkan Profesionalisme Guru.}

MGMP sosiologi Kota kupang mengalami beberapa kendala dalam meningkatkan profesionalisme guru sosiologi, sehingga wadah ini tidak berjalan dengan aktif sejak akhir tahun 2018 lalu hingga sampai dengan saat ini, berdasarkan hasil penelitian diketahui beberapa kendala yang dihadapi oleh MGMP Sosiologi Kota Kupang diantaranya: (a) kurangnya motivasi dan dorongan guru sosiologi untuk meningkatkan profesionalisme melalui wadah MGMP sosiologi Kota Kupang; (b) sulitnya penyesuaian jadwal pertemuan dari masing-masing guru karena kesibukan guru-guru sosiologi dalam memenuhi 24 jam pelajaran setiap minggu di sekolah belum lagi dengan jadwal mengajar antara guru yang satu dengan guru sosiologi lainnya tentu berbeda-beda sehingga jika guru-guru sosiologi mengikuti kegiatan yang diadakan oleh MGMP sosiologi maka guru harus mengorbankan jam mengajarnya di kelas dan dapat merugikan para peserta didik; (c) keterbatasan dana karena kegiatan-kegiatan yang diadakan dalam suatu organisasi tidak dapat berjalan dengan baik tanpa adanya dana, dari hasil wawancara dengan sekretaris MGMP sosiologi mengungkapkan bahwa MGMP sosiologi sendiri belum mendapatkan dana dari terkait, berbeda dengan wadah MGMP lainya yang sudah terlebih dahulu mandapatkan dana bantuan dari dinas sehingga kegiatan yang menjadi program MGMP sosiologi didanai dari hasil iuran guru-guru sosiologi; dan (d) kurangnya pengawasan dari Dinas pendidikan Provinsi NTT terhadap wadah MGMP sosiologi.

\section{KESIMPULAN}

Berdasarkan hasil penelitian dan pembahasan dapat disimpulkan bahwa, MGMP sosiologi Kota Kupang berperan aktif dalam meningkatkan kinerja guru sosiologi, hal ini ditunjukkan dengan peran yang dilakukan oleh MGMP sosiologi diantaranya: melakukan pengkajian terhadap inovasi model dan media pembelajaran, pelatihan dalam pembuatan perangkat pembelajaran, diklat, workshop, pembuatan soal-soal ujian, pelatihan dan pendalaman kurikulum 2013 beserta model dan evaluasinya, dan melakukan bimbingan terbatas/latihan mengajar secara bergantian yang dibimbing oleh guru senior. Dengan demikian MGMP sosiologi berperan serta dalam meningkatkan kompetensi profesionalisme guru. Beberapa kendala yang dihadapi dalam melaksanakan perannya yaitu: (a) kurangnya motivasi guru sosiologi dalam meningkatkan profesionalisme melalui wadah MGMP, (b) kurangnya kerja sama antara anggota dengan badan pengurus 
MGMP, (c) jadwal pertemuan wadah MGMP sosiologi yang bertepatan dengan jam mengajar guru sosiologi di sekolah, (d) kurangnya dana operasional dalam menunjang kegiatan yang diadakan oleh MGMP sosiologi di Kota Kupang.

\section{REFERENSI}

Adriyani, W. (2019). Peranan Musyawarah Guru Mata Pelajaran (MGMP) Terhadap Kompetensi Guru Matematika Di Tingkat SMA. Jurnal Pendidikan Kahuripan, 2(1) 68-73

Arba, R., (2018). Peran Musyawarah Guru Mata Pelajaran (MGMP) Dalam Meningkatkan Profesionalisme Guru Pai SMA Kabupaten Sragen. Skripsi S1. Institut Agama Islam Negeri Surakarta. Diakses pada laman http://eprints.iainsurakarta.ac.id/1785/1/FULLTEKS.pdf

Djulaiqha, (2017). Peningkatan Kompetensi Guru IPS (Studi Kasus Di MGMP IPS Kecamatan Cengkareng Jakarta Barat). Jurnal Edukasi IPS, 1(1) 18-23

Farihatul, H., (2016). Peran Musyawarah Guru Mata Pelajaran (MGMP) Untuk Meningkatkan Kompetensi Profesional Guru PAI: Studi Kasus MGMP PAI SMP Negeri Kabupaten Kediri. Jurnal Didaktika Religia, 4(2) 71-75

Fitriani, W., (2013). Efektifitas pembelajaran Mata Pelajaran Muatan Lokal Bordir Pada Siswa Tata Busana Kelas XI Di SMK Negeri 1 Kendal. Jurnal Fashion and Fashion Education, 2(1): 9-10.

Israwati. (2014). Pengaruh Strategi Pembelajaran Dan Motivasi Mengajar Guru Terhadap Hasil Belajar Siswa Kelas Awal SD Negeri 24 Banda Aceh. Jurnal Serambi Ilmu. Vol 19 (2) 87.

Mumainah, N., (2011). Peran Musyawarah Guru Mata Pelajaran (MGMP) Dalam Pengembangan Kompetensi Profesional Guru Sejarah Pada SMA Di Kabupaten Rembang Tahun Ajaran 2010/2011. Diakses pada laman http://lib.unnes.ac.id/5627/1/7723.pdf

Nurdin. (2019). Pelaksanaan MGMP Dalam Meningkatkan Profesional Guru Pendidikan Agama Islam. Jurnal Serambi Ilmu, 2(2) 11-15

Okyulianti. (2017). Peranan Musyawarah Guru Mata Pelajaran Dalam Meningkatkan Kompetensi Profesional Guru IPS SMP di Kota Padang. Skripsi S1. Universitas PGRI Sumatera Barat. Diakses pada laman repo.stkippgri-sumbar.ac.id/id/eprint/2039/

Rosihan, A., (2011). Pengaruh Musyawarah Guru Mata Pelajaran (MGMP) Terhadap Peningkatan Profesionalisme Dan Kinerja Mengajar Guru Sma Negeri Kota Tasikmalaya. Jurnal Administrasi Pendidikan, 13(1) 27-32

Sastria, E., (2011). Peran Musyawarah Guru Mata pelajaran (MGMP) Dalam Pengembangan Kompetensi Profesional Guru Penjas Orkes Pada SMP di Kota Salatiga. Skripsi S1. Universitas Negeri Semarang. Diakses pada laman http://lib.unnes.ac.id/7933/

Wardani, S. (2019). Peran MGMP Matematika Dalam Mengembangkan Profesionalisme Guru. Tesis S2, Institut Agama Islam Negeri Tulungagung. Diakses pada laman http://repo.iaintulungagung.ac.id/13424/ 